\title{
KUALITAS AKUSTIK RUANG UTAMA MASJID SITI AISYAH SURAKARTA
}

Nur Utami Isyana Dewi

Program Studi Arsitektur, Fakultas Teknik, Universitas Muhammadiyah Surakarta e-mail: isyana d@ymail.com

\section{Nur Rahmawati Syamsiyah}

Program Studi Arsitektur, Fakultas Teknik, Universitas Muhammadiyah Surakarta e-mail: nur rahmawati@ums.ac.id

\begin{abstract}
ABSTRAK
Masjid sebagai bangunan ibadah umat Islam dituntut untuk nyaman. Salah satu kenyamanan adalah terhadap aspek suara seperti tingkat kebisingan rendah, distribusi bunyi merata serta kenyamanan terhadap pengguna ruang. Fokus penelitian ini adalah menganalisis tingkat tekanan bunyi, kinerja elemen serta evaluasi subjektif kenyamanan bunyi oleh pengguna ruang utama Masjid Siti Aisyah Surakarta. Penelitian menggunakan pengukuran tingkat tekanan bunyi dan analisis pemetaan bunyi dalam ruang serta persepsi keruangan dari pengguna melalui kuesioner secara online. Pengukuran tingkat tekanan bunyi menggunakan Sound Level Meter dan pemetaan bunyi menggunakan aplikasi Surfer 11. Hasil pengukuran bahwa intensitas bunyi ruang rata-rata yaitu sebesar $53.30 \mathrm{dBA}$ saat ruang dalam kondisi sedikit aktivitas serta $70.45 \mathrm{dBA}$ pada saat ruang dalam kondisi ada aktivitas kajian agama. Hasil pemetaan saat ruang sedikit aktivitas adalah bunyi terdistribusi merata, namun saat ruang digunakan untuk kajian, terjadi interferensi gelombang berupa penguatan bunyi, yang menyebabkan kebisingan. Hasil kuesioner menunjukkan bahwa pengguna Masjid Siti Aisyah tidak terganggu dengan kebisingan, baik bising yang bersumber dari dalam bangunan maupun dari luar bangunan, karena pengguna masjid sudah mempersiapkan diri dengan niat untuk beribadah sehingga dapat beradaptasi dengan keadaan di ruang utama masjid Siti Aisyah.
\end{abstract}

KATA KUNCI: akustik, geometeri, kebisingan,masjid, material

\section{PENDAHULUAN}

Masjid berdasarkan akar katanya mengandung arti tunduk dan patuh, maka hakekat dari masjid adalah tempat melakukan segala aktivitas yang berkaitan dengan kepatuhan kepada Allah semata (Bachrudin, 2014). Masjid sebagai tempat ibadah umat Islam menuntut agar memberikan kenyamanan semaksimal mungkin bagi penggunanya sehingga kenyamanan ruang ibadah dapat membuat lebih khusyuk atau menjadikan kegiatan yang dilakukan terasa lebih dekat dengan Allah. Salah satu faktor yang bisa mempengaruhi tingkat kenyamanan tersebut adalah bunyi atau suara.

Kenyamanan bunyi dipengaruhi oleh tingkat tekanan bunyi, dimana tingkat tekanan bunyi memiliki ambang batas kebisingan. Bunyi dapat dikatakan bising, karena melebihi nilai ambang kebisingan. Syarat bising yang dapat diterima untuk masjid (sebagai bangunan ibadah), yaitu 25-35 dBA (Kinsler, Frey, Coppens, \& Sanders, 2000, p. 364).

Kebisingan berarti pula merupakan suara yang tidak diinginkan atau tidak dikehendaki serta dapat mengganggu pendengaran (Gabriel, 2001; Suma'mur, 2009). Pedoman Higiene Perusahaan dan Kesehatan Kerja-HIPERKES (Suma'mur, 2009) menuliskan bahwa efek kebisingan berpengaruh negatif, dimana gangguan secara umum dalam kehidupan sehari-hari dapat mengganggu konsentrasi dan menyebabkan pengalihan perhatian sehingga tidak fokus kepada kegiatan yang sedang dikerjakan atau dilakukan. Pumar (2019) dalam jurnalnya menyatakan bahwa kebisingan yang terpapar terhadap jamaah yang melakukan suatu aktivitas, akan mengakibatkan penurunan performa aktivitas yang dapat menyebabkan penurunan tingkat konsentrasi jamaah dalam menjalankan aktivitas pada ruangan, sehingga dalam perancangan masjid perlu diperhatikan kenyamanan terhadap suara.

Surakarta adalah salah satu kota di Indonesia yang memiliki fenomena menarik dalam hal perkembangan Islam. Surakarta menjadi barometer Indonesia. Perkembangan Islam salah satunya dapat dilihat dari perkembangan keberagaman bentuk masjid. Salah satu bentuk masjid yang mudah teramati karena karakteristiknya yang khas adalah Masjid Siti Aisyah. Masjid ini diresmikan pada tanggal 29 Desember 2018, berbentuk geometri yang unik berupa kubus, sehingga dikenal sebagai Masjid Kotak (lihat gambar 1). Ruang utama Masjid Siti Aisyah berada di lantai satu, yang merupakan ruang untuk aktivitas shalat lima waktu (khusus laki-laki/ikhwan), kajian rutin, akad nikah serta kegiatan agama lainnya. Sedangkan ruang sholat untuk perempuan/akhwat 
berada di lantai dua. Banyaknya aktivitas yang terjadi di ruang utama Masjid Siti Aisyah, menuntut kenyamanan bagi pengguna ruang. Salah satu faktor kenyamanan adalah terhindar dari gangguan kebisingan, baik kebisingan dari dalam masjid maupun kebisingan dari luar masjid.

Ruang utama Masjid Siti Aisyah memiliki interior yang menonjolkan kesan mewah dengan penggunaan material marmer dan kayu ukir. Penelitian Syamsiyah, Dharoko dan Utami (2014) menunjukkan bahwa bentuk geometri ruang, dan material elemen ruang serta bentuk permukaan elemen ruang dinding, celling sebetulnya dapat berfungsi untuk keindahan ruang dalam, yang sekaligus akan berpengaruh terhadap kinerja akustik ruang. Keadaan ruang dalam Masjid Siti Aisyah pada bagian lantai dan dinding diselesaikan dengan marmer yang dipoles licin, sehingga diduga memiliki pengaruh terhadap akustik ruang. Hal ini sesuai dengan penelitian Ismail (2013), yang mengatakan bahwa umumnya masjid-masjid di Arab Saudi hanya mementingkan faktor estetis untuk aspek arsitektural dan visual. Material finishing yang memiliki karakteristik visual yang mewah dan mahal, namun ternyata buruk untuk akustik ruang. Masjid Dewala Kuwait mencapai waktu dengung 3-6 detik, sedangkan Masjid Damascus mencapai 1 detik.

Keadaan Masjid Siti Aisyah serupa dengan masjid-masjid yang telah diteliti oleh Ismail (2013). Masjid Siti Aisyah memiliki penyelesaian dinding dan lantai berbahan marmer yang bersifat reflektor tersebut menarik untuk diteliti, sehingga penelitian ini bertujuan untuk mengetahui kondisi kenyamanan ruang terhadap tingkat tekanan bunyi yang terjadi pada ruang utama atau ruang ibadah ikhwan. Tingkat kenyamanan didasarkan pada pengukuran dan analisis pemetaan bunyi serta evaluasi subjektif dari pengguna ruang (jamaah masjid).

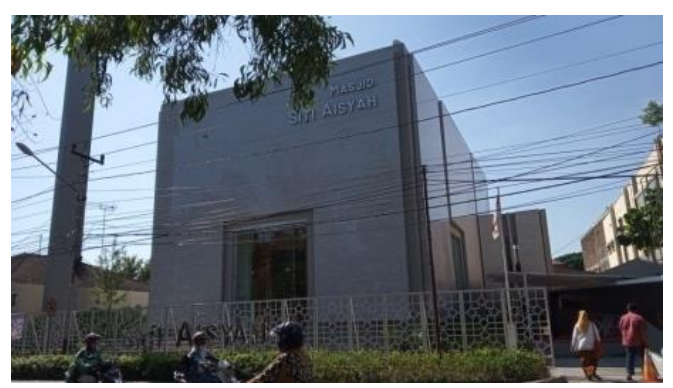

Gambar 1. Tampak Majid Siti Aisyah Manahan Solo (Sumber: Dokumen penulis, 2019)

\section{MASJID}

Masjid berasal dari bahasa Arab. Kata pokoknya 'sujudan', fi'il madhinya adalah 'sajada' yang berarti 'ia telah sujud', patuh, taat serta tunduk penuh hormat dan takzim (Shihab,1997,h.459). Fungsi utama masjid adalah tempat sujud kepada Allah SWT, tempat sholat, tempat beribadah dan tempat mendekatkan diri kepada Allah SWT. Fungsi masjid yang lain adalah tempat untuk I'tikaf, tempat bermusyawarah, tempat membina keutuhan ikatan jamaah, tempat untuk meningkatkan kecerdasan dan ilmu pengetahuan/agama, tempat pembinaan dan pengembangan kader pemimpin umat, tempat memberikan pelayanan dan pertolongan kepada masyarakat serta tempat mengumpulkan dana, seperti zakat, sodaqoh, infak dan sebagainya (Ayub, 1996, p. 7; Gazalba, 1962, pp. 121-125).

Fungsi masjid beragam, yang setiap kegiatan menuntut karakteristik kenyamanan bunyi yang berbeda. Namun demikian semua kegiatan yang ada di dalam masjid semestinya didukung oleh kualitas bunyi yang dapat menenangkan dan menentramkan hati serta membuat khusyuk beribadah.

\section{TINJAUAN PUSTAKA}

Bunyi atau sound, dan suara atau voice, memiliki pengertian yang sama (Gabriel, 2001). Bunyi yang memenuhi kualifikasi nyaman untuk didengar dapat dimanfaatkan dalam kehidupan sehari-hari antara 40$60 \mathrm{~dB}$ (batas yang nyaman didengar). Sementara itu bunyi yang tidak berkualitas atau buruk ialah bunyi yang bersifat mengganggu kesehatan pendengaran, dan memiliki intensitas $>70 \mathrm{~dB}$.

Bunyi terjadi karena adanya objek atau benda yang bergetar sehingga menimbulkan gesekan dengan zat di sekitarnya. Tiga hal yang harus ada untuk dapat mendengar bunyi yaitu sumber atau objek yang bergetar, medium perambat serta pendengar atau penerima bunyi (Mediastika, 2005). Medium perambatan bunyi yang dirasakan dalam kehidupan sehari-hari adalah udara dan benda padat. Benda padat di dalam sebuah bangunan diantaranya berupa elemen ruang dinding, lantai dan langit-langit. Material elemen ruang yang digunakan berpengaruh terhadap kinerja mediua perambatan bunyi, apakah akan memperkuat bunyi atau melemahkan bunyi.

Penguatan dan pelemahan bunyi disebut interferensi gelombang bunyi (Gabriel, 2001), yang sangat mungkin terjadi dalam sebuah ruang, yaitu berupa bertemunya dua gelombang bunyi pada fase yang sama dan fase yang berlawanan (berbeda). Interferensi konstruktif terjadi ketika dua gelombang bertemu pada fase yang sama dan akan menguatkan bunyi, sedangkan interferensi destruktif terjadi ketika dua gelombang bertemu pada fase yang berlawanan dan akan melemahkan bunyi. Interferensi gelombang bunyi dapat bersifat membangun ataupun merusak. Bersifat membangun jika berbeda fase kedua gelombang sama sehingga gelombang baru yang berbentuk adalah penjumlahan dari kedua gelombang tersebut. Bersifat merusak jika fasenya 
adalah $180^{\circ}$, sehingga kedua gelombang saling menghilangkan (Fadhilla \& Kasli, 2017).

\section{KEBISINGAN}

Kebisingan adalah suara-suara yang tidak disenangi atau tidak dikehendaki (Gabriel, 2001; Kinsler, Frey, Coppens, \& Sanders, 2000). Penilaian kebisingan dapat dilakukan secara objektif dan subjektif. Penilaian kebisingan secara subjektif akan berbeda, tergantung watak, temperamen, psikis dan kebiasaan seseorang dalam mendengarkan bunyi. Penilaian kebisingan secara objektif merupakan penilaian secara pasti dengan pengukuran menggunakan alat ukur bunyi seperti Sound Level Meter dan dilakukan sesuai dengan prosedur yang telah ditentukan. Rekomendasi nilai kebisingan yang dapat diterima di dalam ruang dan masuk dalam kategori nyaman ada dalam tabel 1.

Table 1. Rekomendasi nilai bising yang dapat diterima di dalam ruangan

\begin{tabular}{lc}
\hline \multicolumn{1}{c}{ Location } & $\begin{array}{c}\text { Noise Criteria } \\
\text { (NCB) }\end{array}$ \\
\hline Concert hall, recording studio & $10-15$ \\
\hline Music room, legitimate theater & $25-30$ \\
\hline $\begin{array}{l}\text { Church, courtroom, conference } \\
\text { room, hospital, bedroom }\end{array}$ & $25-35$ \\
\hline $\begin{array}{l}\text { Library, private office, living room, } \\
\text { classroom }\end{array}$ & $30-40$ \\
\hline $\begin{array}{l}\text { Restaurant, movie theater, retail } \\
\text { shop, bank }\end{array}$ & $35-45$ \\
\hline $\begin{array}{l}\text { Gymnasium, clerical office } \\
\text { Shops, grage }\end{array}$ & $40-50$ \\
\hline
\end{tabular}

(Sumber: Kinsler, et.al, 2000, p. 364)

\section{METODE PENELITIAN}

Penelitian dilakukan dengan mengamati secara langsung situasi dan kondisi nyata di lokasi. Penelitian ini menggunakan analisis kuantitatif dan spasial. Analisis kuantitatif yaitu melakukan perhitungan tingkat kebisingan pada ruang ibadah Masjid Siti Aisyah. Sementara itu, analisis spasial yaitu memetakan tingkat kebisingan melalui aplikasi Surfer 11. Guna menguatkan hasil pengukuran objektif, dan penelitian ini dilengkapi hasil kuesioner responden malalui link aplikasi google form.

Sebelum melakukan penelitian perlu ditentukan titik pengukuran, yang didasarkan pada denah sebagai acuan dengan memberikan grid atau garis garis potong. Grid yang dihasilkan menjadi 9 bagian, tetapi dalam penelitian ini hanya digunakan 8 bagian saja. Titik ukur T8 adalah letak sumber bunyi, posisi penceramah. Jarak antar titik ukur adalah 4 meter dan jarak titik ukur terhadap dinding adalah 2 meter (lihat gambar 2). Titik ukur atau titik berdasarkan sampling aktivitas pengguna (jamaah). Titik ukur atau titik sampling berjumlah 8 titik yang merupakan lokasi jama'ah sebagai pendengar suara, baik saat khutbah, sholat atau kajian keagamaan rutin.

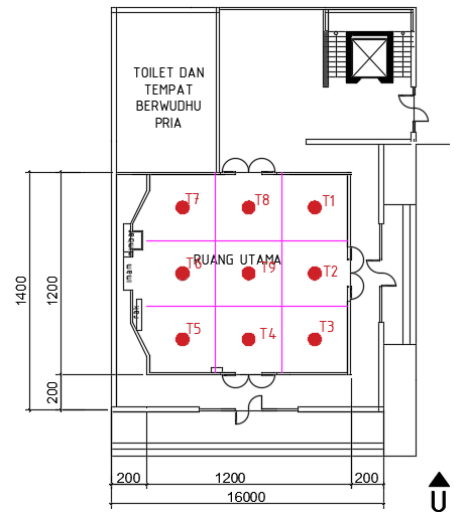

Gambar 2. Denah dan titik ukur objek penelitian masjid Siti Aisyah (Sumber: Dokumen Penulis, 2019)

Penelitian ini menggunakan beberapa alat guna mempermudah dalam proses pengumpulan data, antara lain:

1. Alat tulis digunakan untuk mencatat data hasil wawancara dengan narasumber selama dilakukannya penelitian ini

2. Kamera yang digunakan sebagai alat dokumentasi data berupa gambar atau foto untuk melengkapi dan mendukung data-data yang diperlukan.

3. Stopwatch digunakan untuk menghitung waktu dalam penelitian.

4. Aplikasi Microsoft office excel digunakan untuk mengukur rata-rata intensitas bunyi pada setiap titik ukur.

5. Aplikasi Surfer 11. merupakan aplikasi yang digunakan untuk memetakan kebisingan ruang dan memudahkan untuk menganalisa.

6. Aplikasi google form untuk membuat kuesioner dan menjaring pendapat responden.

7. Sound level meter digunakan untuk mengukur tingkat tekanan bunyi di lokasi penelitian.

Data yang diperoleh kemudian dihitung menggunaka rumus intensitas bunyi rata-rata menggunkan Microsoft office excel. Untuk mengukur intensitas bunyi rata-rata dapat menggunakan persamaan (Lawrence, 1967):

$$
L_{t}=10 \log \left[_{i=1}^{n} \sum_{i} \times 1^{L 1 / 10}\right]
$$

Keterangan:

$\mathrm{Lt}=$ intensitas bunyi rata-rata

$\mathrm{Li}=$ intensitas bunyi internal

$\mathrm{n}=$ jumlah sumber bunyi 
Data hasil pengukuran rata-rata intensitas bunyi dipetakan menggunaka aplikasi Surfer 11. Pemberian kuesioner menggunakan aplikasi google form dan dibagikan melalui link https://forms.gle/XqMkYsisyWzhNmh4A.

\section{PENGARUH GEOMETRI RUANG DAN MATERIAL TERHADAP AKUSTIK RUANG}

Mariani dan Rauf (2008) menyatakan tingkat bising akibat pantulan di dalam ruang masjid dipengaruhi oleh bentuk geometri ruang, dimensi dan volume ruang serta bahan permukaan yang melingkupi ruang. Abdou (2003) menyebutkan bahwa kinerja akustik ruang masjid sangat tergantung dari bentuk geometri ruang utama masjid. Terdapat 5 bentuk geometri ruang yang diteliti dengan bentuk dan volume yang sama yaitu persegi panjang (rectangle), bujur sangkar (square), trapezium (trapezoid), segi enam (hexagon) dan segi delapan (octagon). Bentuk bujur sangkar adalah yang terbaik dalam memberikan distribusi bunyi merata hingga terdengar dengan baik diseluruh bagian ruang. Bentuk octagon adalah yang paling rendah memberikan distribusi bunyi merata, karena terbentuk interferensi gelombang bunyi yang saling menguatkan di tengah ruang dan beberapa sisi ruang. Selain bentuk geometri ruang, bentuk ceiling berpengaruh juga pada kenyamanan akustik.

Dalam hasil penelitian Syamsiyah (2014) menyatakan karpet, bata expose, jendela dan udara luar dapat berpengaruh terhadap penyerapan bunyi. Penelitian Suharyani dan Mutiari (2013) menyebutkan bahwa perbedaan bentuk anyaman daun pisang berpengaruh terhadap terbentuknya karakteristik terkstur dan lubang/pori-pori pada partisi dinding. Semakin banyak pori-pori pada partisi, maka penyerapan bunyi lebih efisien. Selain itu ketebalan, dan jarak lapisan dinding juga menentukan optimalisasi tingkat peredaman terhadap bunyi. Penelitian lain terkait material adalah penyelesaian permukaan elemen ruang yang berbahan licin, kaku, keras, adalah penyebab perolehan nilai parameter akustik ruang yang buruk. Oleh sebab itu bidang akustik yang memiliki fungsi penyerapan dioptimalkan di masjid agar memenuhi keinginan lingkungan yang tenang (Gul \& Caliskan, 2013)

\section{HASIL DAN PEMBAHASAN}

\section{Pengukuran intensitas bunyi}

Pengukuran dilakukan dua kali, saat aktivitas padat (temporer) dan saat aktivitas tidak padat (rutin). Aktivitas padat ketika diadakan kajian keagamaan, dan aktivitas tidak padat saat pelaksanaan sholat dzuhur berjamaah. Dua kondisi sengaja dipilih, untuk melihat perbandingan dari dua kondisi tersebut.
Perbandingan meliputi sebaran bunyi dan intensitas bunyi.

\section{Pengukuran saat keadaan tidak padat}

Pengukuran dilakukan dalam kondisi ruang kosong, setelah selesai dilakukan jamaah sholat dzuhur. Terdapat 9 orang di dalamnya; 5 orang beribadah sholat dzuhur, 2 orang duduk berdoa/berdzikir dan 2 orang pengamat (peneliti). Kondisi ruang utama masjid terlihat pada gambar 3.

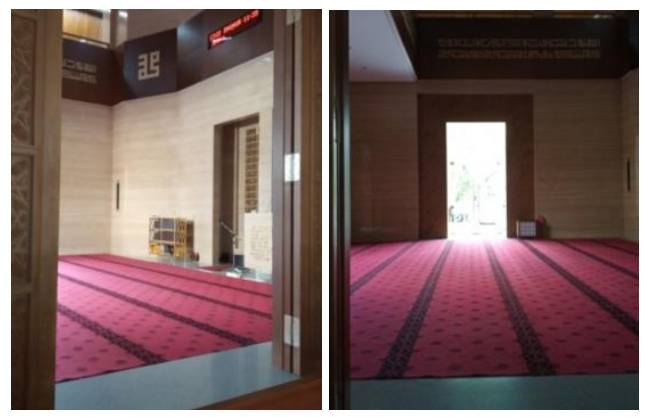

Gambar 3.Kondisi ruang utama sholat saat setelah sholat dzuhur (Sumber: Dokumen Penulis, 2019)

Data pengukuran pada setiap titik ukur sebagaimana tabel 2 dan gambar 4:

Table 2. Rata-rata intensitas bunyi di setiap titik ukur saat ruang tidak padat

\begin{tabular}{cc}
\hline Titik & $\begin{array}{c}\text { Rata-Rata Intensitas Bunyi tiap } \\
\text { titik ukur (dBA) }\end{array}$ \\
\hline Titik 1 & 48.81 \\
\hline Titik 2 & 55.82 \\
\hline Titik 3 & 55.94 \\
\hline Titik 4 & 55.4 \\
\hline Titik 5 & 53.84 \\
\hline Titik 7 & 53.27 \\
\hline Titik 8 & 49.36 \\
\hline Titik 9 & 49.45 \\
\hline
\end{tabular}

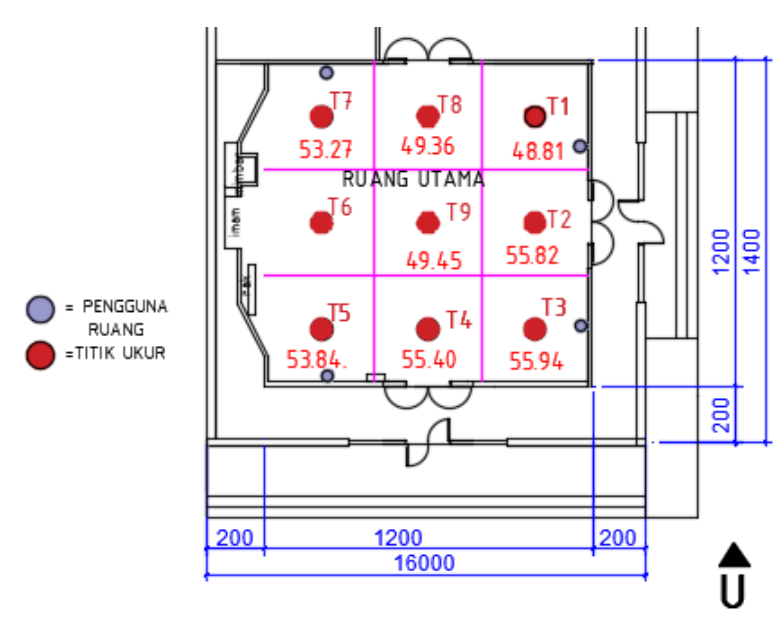

Gambar 4. Rata-rata intensitas bunyi di setiap titik ukur saat ruang tidak padat (Sumber: Dokumen Penulis, 2019) 
Hasil pengukuran intensitas bunyi rata-rata $\mathrm{d}$ dalam ruang ibadah pria disaat tidak terjadi aktivitas yang padat adalah $53.30 \mathrm{dBA}$.

\section{Pengukuran saat keadaan padat}

Pengukuran yang dilakukan dalam kondisi ruang digunakan untuk kegiatan kajian keagamaan. Terdapat 93 orang di dalam ruang utama sholat (ruang ikhwan); 1 orang pembicara 2 orang peneliti dan 90 orang sebagai peserta kajian/ pendengar.

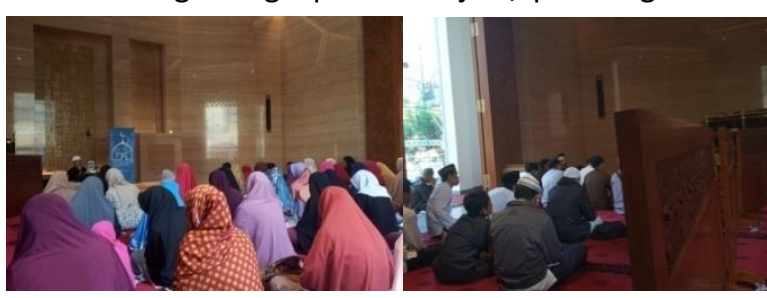

Gambar 5. Kondisi ruang saat aktivitas kajian (padat pengunjung) (Sumber: Dokumen Penulis, 2019)

Data pengukuran rata-rata pada setiap titik ukur di ruang kegiatan utama adalah sebagaimana tabel 3 dan gambar 6 .

Table 3. Table Rata-rata intensitas bunyi di setiap titik ukur saat ruang padat

\begin{tabular}{cc}
\hline Titik & $\begin{array}{c}\text { Rata-Rata Intensitas Bunyi tiap } \\
\text { titik ukur (dBA) }\end{array}$ \\
\hline Titik 1 & 69.27 \\
\hline Titik 2 & 70.08 \\
\hline Titik 3 & 70.56 \\
\hline Titik 4 & 63.21 \\
\hline Titik 5 & 68.05 \\
\hline Titik 7 & 72.23 \\
\hline Titik 8 & 73.49 \\
\hline Titik 9 & 69.88 \\
\hline
\end{tabular}

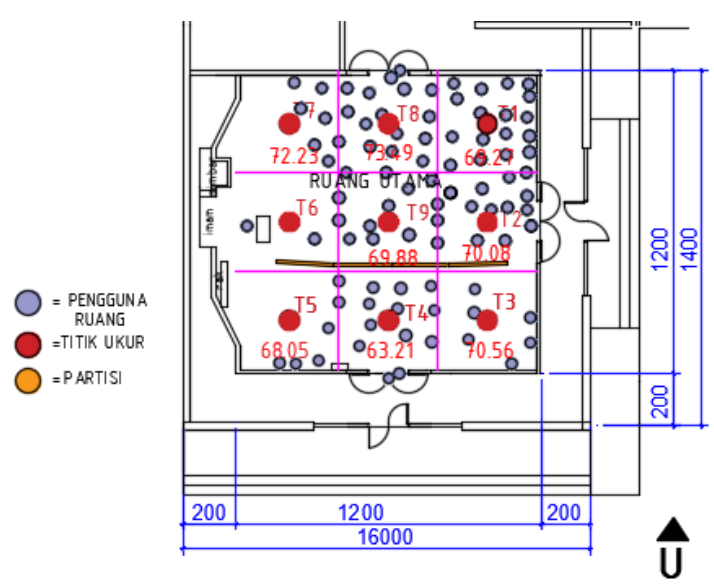

Gambar 6. Rata-rata intensitas bunyi di setiap titik ukur saat ruang tidak padat

(Sumber: Dokumen Penulis, 2019)
Hasil pengukuran intensitas bunyi rata-rata di dalam ruang ibadah pria disaat terjadi aktivitas yang padat, berupa kajian keagamaan, adalah 70.45 dBA

\section{Pemetaan kebisingan}

Data hasil pengukuran dipetakan dengan menggunakan Software Surfer 11, sebagaimana terlihat dalam gambar 7 dan 8 .

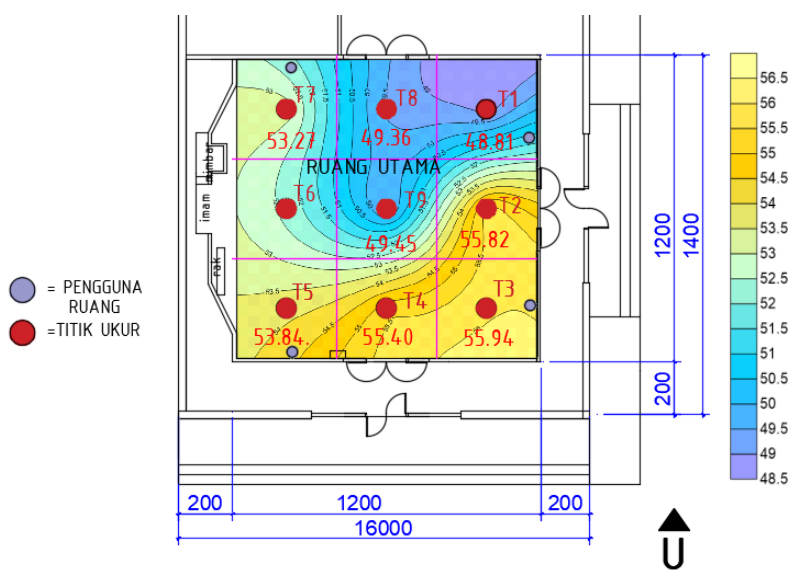

Gambar 7. Mapping SPL saat ruang tidak padat aktivitas Sumber: Dokumen Penulis, 2019

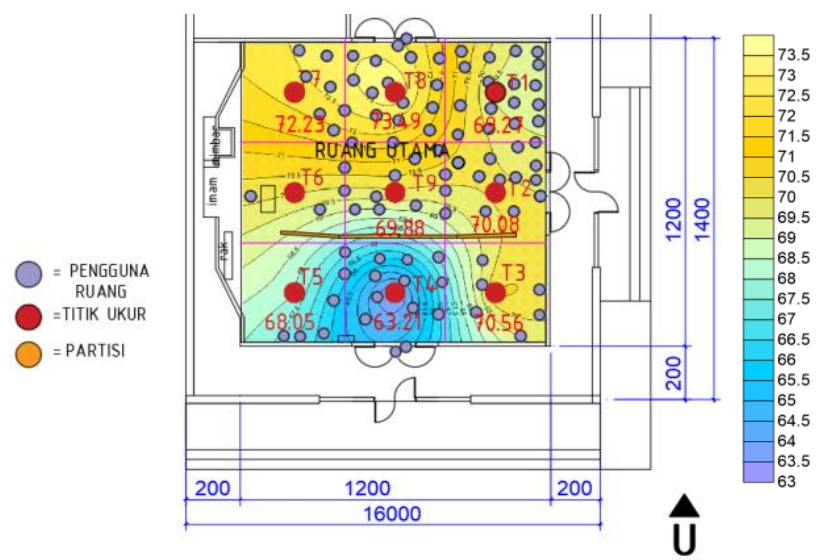

Gambar 8. Mapping SPL saat ruang padat aktivitas Sumber: Dokumen Penulis, 2019

Kedua mapping menunjukkan keadaan yang berbeda, sebagai dampak dari keberadaan aktivitas di dalamnya. Keadaan pertama (gambar 7), mapping menunjukkan iso-akustik yang memiliki pola tetap, ritmis jarak yang sama antar garis akustik. Berbeda dengan mapping saat ruang utama digunakan kajian agama. Terbentuk interferensi gelombang, baik saling menguatkan, maupun saling melemahkan (gambar 8). Posisi ruang dekat pintu masuk secara logika akan bising, karena dekat juga dengan jalan raya, namun justru terjadi sebaliknya, yaitu terjadi pelemahan bunyi. Posisi dekat pintu masuk justru penuh dengan jamaah laki-laki yang duduk, yang sebetulnya menjadi 
media penyerapan bunyi yang baik. Tubuh manusia mampu menyerap bunyi 50\% (Satwiko, 2004). Keadaan berbeda dengan keadaan tempat jamaah perempuan, dimana terjadi penguatan bunyi.

\section{KUESIONER}

Kuesioner melalui aplikasi google form, mendapat tanggapan dari 38 responden. Responden adalah mereka yang sudah pernah mengunjungi Masjid Siti Aisyah Surakarta. Jawaban responden menjadi acuan dalam menilai subjektivitas terhadap kebisingan pada masjid, di samping untuk mengetahui kualitas akustik di dalam ruang utama masjid.

Hasil kuesioner online tentang kenyamanan masjid secara umum adalah $47.4 \%$ menyatakan sangat nyaman, $44.7 \%$ menyatakan nyaman dan $7.9 \%$ menyatakan biasa. Responden yang berpendapat bahwa suara imam/khatib terdengar jelas sejumlah 94.7\%, dan menyatakan tidak jelas sejumlah 5.3\%. Responden pun mengatakan bahwa suara imam atau khatib terdengar jelas artikulasinya.

Sedangkan secara umum jumlah responden menilai bahwa kenyamanan ruang masjid dari aspek suara adalah $48.6 \%$ responden mengatakan nyaman, $45.9 \%$ responden menyatakan biasa dan $5.4 \%$ responden menyatakan bising.

\section{PEMBAHASAN}

Pengukuran intensitas bunyi di ruang utama Masjid Siti Aisyah memperoleh hasil rata-rata yang cukup tinggi mencapai $53.30 \mathrm{dBA}$ dan $70.45 \mathrm{dBA}$. Nilai tersebut jauh di atas syarat bising yang dapat diterima untuk masjid (sebagai bangunan ibadah), yaitu 25-35 dBA (Kinsler, Frey, Coppens, \& Sanders, 2000, p. 364).

Berdasarkan hasil pemetaan pada saat ruangan tidak banyak aktivitas di dalamnya terlihat bahwa bunyi yang terjadi pada ruang tersebar secara merata atau teratur, hal ini dibuktikan dengan tidak adanya interferensi gelombang bunyi yang terjadi pada hasil pemetaan. Pada titik ukur T2, T3, T4 dan T5 terdapat kenaikan intensitas bunyi, pada posisi titik ukur berada di dekat jalan raya. Tingginya nilai intensitas bunyi kemungkinan besar juga disebabkan oleh material yang terdapat pada bagian pintu banguan masjid yang terbuat dari kaca dan dinding marmer.

Sedangkan hasil pemetaan saat adanya kegiatan kajian terlihat bahwa penyebaran bunyi yang terjadi pada ruang tersebar tidak merata, hal ini dibuktikan dengan adanya dua interferensi gelombang bunyi yang terjadi pada titik ukur T4 (tempat jamaah lakilaki) dan T8 (tempat jamaah perempuan). Interferensi gelombang bunyi yang terjadi pada titik ukur T4 merupakan pelemahan bunyi, sedangkan pada titik ukur T8 merupakan penguatan bunyi. Pelemahan bunyi terjadi karena adanya dua gelombang yang saling meniadakan. Sekalipun letak titik ukur T4 dekat jalan raya, namun perolehan nilai SPL rendah. Hal ini sangat mungkin terjadi karena gelombang bunyi dari jalan raya bertemu dengan gelombang bunyi dari dalam ruang masjid, dan saling melemahkan. Sedangkan untuk titik ukur T8 adanya interferensi yang menyebabkan naiknya intensitas bunyi yang kemungkinan disebabkan oleh sumber-sumber yang berada di dalam ruang, seperti percakapan antar jamaah perempuan. Pengamatan di lapangan memperlihatkan jamaah perempuan (ibu-ibu) saling berbicara satu dengan lainnya, sehingga bunyi di titik ukur T8 terdengar lebih keras (berisik).

Penilaian subjektif terhadap kenyamanan ruang masjid dari aspek bunyi, memang menunjukkan perbedaan cukup signifikan. Sejumlah $48.6 \%$ menyatakan nyaman, $45.9 \%$ menyatakan bisa saja dan $5.4 \%$ menyatakan bising. Perbedaan penilaian yang mencolok dapat terjadi karena beberapa faktor, seperti suasana hati, psikis, kebiasaan dalam mendengar bunyi maupun fokus terhadap sumber bunyi. Keadaan responden ini yang lepas dari pengamatan, sehingga jawaban dari responden masih perlu ditelaah kembali. Terdapat distorsi waktu antara pengisian kuesioner dengan kunjungan responden ke masjid. Namun keadaan ini dapat diterima, sebab hasil kuesioner di-cross-check ulang dengan wawancara bebas, dan hasilnya menjadi penunjang dari interpretasi hasil pengukuran secara objektif.

Pengukuran SPL ruang masjid memperlihatkan hasil sesuai pendapat Abdou (2003), bahwa bentuk geometri ruang bujur sangkar adalah yang terbaik dalam memberikan distribusi bunyi merata hingga terdengar dengan baik di seluruh bagian ruang. Bentuk pemetaan bunyi pada ruang utama masjid Siti Aisyah menunjukkan pola teratur atau merata. Bahan penggunaan material yang keras dan licin di masjid ini, yaitu granit, marmer, kayu, tidak menyebabkan penyebaran bunyi tidak teratur atau menyebabkan interferensi gelombang bunyi, melainkan tetap menunjukkan hasil yang baik, merata ke seluruh bagian ruang. Keteraturan atau kemerataan bunyi yang tersebar pada ruang utama masjid, salah satunya disebabkan geometri ruang dan material penutup elemen dalam ruang. Penggunaan karpet di lantai dapat berfungsi sebagai media penyerap bunyi, sesuai hasil penelitian Syamsiyah, Dharoko, Utami (2014), dan didukung pendapat Gul \& Caliskan (2013), bahwa material interior masjid lebih diutamakan bahan yang menyerap bunyi.

\section{KESIMPULAN}

Masjid Siti Aisyah yang berbentuk kotak, dengan elemen ruang berbahan licin, keras dan getas, 
ternyata mampu menunjukkan kinerjanya dalam memberikan kenyamanan akustik. Sekalipun hasil pengukuran SPL memperoleh nilai melebihi standar yang disyaratkan, namun hasil analisis spasial berupa pemetaan SPL menunjukkan kemerataan dan keteraturan bunyi, yang menyebar ke seluruh bagian ruang.

Pengukuran intensitas bunyi ruang saat aktivitas tidak padat adalah $53.30 \mathrm{dBA}$, dan saat padat adalah $70.45 \mathrm{dBA}$, sementara itu standar yang disyaratkan 25-35 dBA. Persepsi kenyamanan akustik diberikan responden melalui kuesioner online dan wawancara langsung, yang cukup memberikan nilai baik kepada masjid ini. Hampir separuh dari jumlah responden menyatakan bahwa masjid memiliki tingkat kenyamanan yang baik dari aspek akustik. Kenyamanan yang dirasakan responden/ jamaah sesungguhnya lebih disebabkan kesiapan jamaah secara psikis dan fisik sejak memasuki masjid dan berniat untuk beribadah. Konsentrasi beribadah dan mampu beradaptasi dengan keadaan apapun, menyebabkan bunyi bising, menjadi tidak terasa mengganggu.

Berdasarkan hasil pengukuran tingkat tekanan bunyi yang melebihi standar, maka perlu diadakan perbaikan masjid, baik interior maupun eksterior. Diperlukan menambahkan ornament penyerap bunyi pada dinding, perlu adanya pemberian barrier baik berupa vegetasi, pagar penghalang dan lainnya guna mengurangi bunyi yang berasal dari luar bangunan.

\section{DAFTAR PUSTAKA}

Abdou, A. A. (2003). Comparison of the Acoustical Performance of Mosque Geometry Using Computer Model Studies. Eighth International IBPSA Conference, (pp. 39-46). Eindhoven, Netherlands.

Bachrudin, R. A. (2014). Penerapan Elemen-Elemen Arsitektur Masjid Kesultanan Pada MasjidMasjid Di Pulau Ternate. Agora, Jurnal Arsitektur, Vol.14, No.2 , 43-64.

Fadhilla, A. R., \& Kasli, E. (2017). Interferensi Gelombang Bunyi pada Pipa Organa Tertutup Prosiding Seminar Nasional MIPA III , 453-458.

Gabriel, J. (2001). Fisika Lingkungan. Jakarta: Hipokrates.

Gul, Z. S., \& Caliskan, M. (2013). Impact of design decision on acoustical comfort parameters: Case study of Dogramacizade Ali Pasa Mosque. Applied Acoustics , 834-844.

Kinsler, L. E., Frey, A. R., Coppens, A. B., \& Sanders, J. V. (2000). Fundamentals of Acoustics. USA: John Wiley \& Sons Inc.

Lawrence, A. (1967). Architectural Acoustics. London: Applied Science Publisher Ltd.
Mariani, \& Rauf, N. (2008). Deskripsi Kondisi Akustik Ruang Masjid Al Markaz Al Islami Makassar. Jurnal SMARTek, Vol. 6, No. 4 , 246-240.

Mediastika, C. E. (2005). Akustika Bangunan: Prinsipprinsip dan Penerapannya di Insonesia. Jakarta: Penerbit Erlangga.

Pumar, A., Baihaqi, Y., Jecki, Handani, G., Saputra, M., Alayat, R., et al. (2019). Analisis Tingkat Kebisingan Tempat Ibadah di Sekitar Perlintasan Rel Kereta di Kota Padang. Jurnal Kapita Selekta Geografi , 35-42.

Suharyani, \& Mutiari, D. (2013). Limbah Pelepah Pisang Raja Susu Sebagai Alternatif Bahan Dinding Kedap Suara . Sinektika Vol.13 No.1, 6268.

Suma'mur. (2009). Higiene Perusahaan dan Kesehatan Kerja (HIPERKES). Jakarta: CV Sagung Seto.

Syamsiyah, N., Utami, S. S., \& Dharoko, A. (2014). Kualitas Akustika Ruang pada Masjid Berkarakter Opening Wall Design. Simposium Nasional RAPI XIII , A-66-A-74. 